\title{
Die chirurgische Wundrevision in BEMA und GOZ
}

Wundheilungsstörungen können nach allen chirurgischen Eingriffen auftreten. In der Mundhöhle finden sich zuhauf meist bakterielle Erreger, die aus unterschiedlichen Gründen die primäre Wundheilung so stark stören, dass eine Wundrevision, d.h. ein erneuter chirurgischer Eingriff im selben Gebiet, erforderlich wird.

Dr. Dr. Josef Schardt // Arzt, Zahnarzt und Abrechnungsexperte, Waldbrunn

Cowohl im BEMA als auch in der GOZ werden für die chirur$\checkmark$ gische Wundrevision folgende Maßnahmen genannt:

$\rightarrow$ Glätten des Knochens,

$\rightarrow$ Auskratzen,

$\rightarrow$ Naht.

In der GOZ werden diese Maßnahmen beispielhaft angeführt. Sie sind daher nicht ausschließlich gemeint. Im Kommentar der Bundeszahnärztekammer sind als weitere Beispiele genannt:

$\rightarrow$ Wundanfrischung,

$\rightarrow$ Umschneidungen,

$\rightarrow$ Entfernung von nekrotischem Gewebe,

$\rightarrow$ Entfernung von kleinen Knochensequestern.

In beiden Gebührenordnungen ist mit „Naht“ das erneute Legen einer Naht gemeint. Die primäre Naht beim operativen Eingriff selbst gehört zur Wundversorgung und ist Bestandteil der Grundleistung, also „im Preis inbegriffen“.

\section{Sequestrotomie? Gibt es eher nicht in der allgemeinzahn- ärztlichen Praxis!}

Ein kleines, abgestoßenes Knochenfragment wird Sequester genannt. Die Entfernung eines solchen Sequesters wird zum

Chirurgische Wundrevision: Was darf wie abgerechnet werden?

\begin{tabular}{|c|c|}
\hline BEMA & GOZ \\
\hline $\begin{array}{l}\text { Nr. } 46 \\
\text { Chirurgische Wundrevision (Glätten } \\
\text { des Knochens, Auskratzen, Naht) }\end{array}$ & $\begin{array}{l}\text { Nr. } 3310 \\
\text { Chirurgische Wundrevision } \\
\text { (z. B. Glätten des Knochens, } \\
\text { Auskratzen, Naht) }\end{array}$ \\
\hline $\begin{array}{l}\text { • als selbstständige Leistung } \\
\text { • in besonderer Sitzung } \\
\text { • je Kieferhälfte oder Frontzahnbereich }\end{array}$ & $\begin{array}{l}\text { - als selbstständige Leistung } \\
\text { • je Operationsgebiet (Raum } \\
\text { einer zusammenhängenden } \\
\text { Schnittführung) } \\
\text { • höchstens zweimal je Kieferhälfte } \\
\text { oder Frontzahnbereich berech- } \\
\text { nungsfähig } \\
\text { - Materialkosten für Anästhesie und } \\
\text { atraumatisches Nahtmaterial zu- } \\
\text { sätzlich berechenbar } \\
\end{array}$ \\
\hline $22,13 €^{*}$ & $12,94 €($ Faktor 2,3) \\
\hline \multicolumn{2}{|c|}{ *z.Z. gültiger Ersatzkassenpunktwert in Hessen: 1,0537€ } \\
\hline
\end{tabular}

Beispiel mit einem scharfen Löffel durchgeführt. Die Abrechnung erfolgt ebenfalls unter BEMA Nr. 46 oder GOZ Nr. 3310. Es sei hier darauf hingewiesen, dass die in BEMA Nr. 52 aufgeführte "Sequestrotomie“ nur bei Vorliegen einer Osteomyelitis abgerechnet werden darf, also in der allgemeinzahnärztlichen Praxis wohl kaum behandelt wird.

Da es sich bei der Wundrevision um schmerzhafte Maßnahmen handelt, ist in der Regel eine Anästhesie erforderlich, die entsprechend abgerechnet wird. Bei Privatpatienten sollten die Materialkosten für Anästhesie und atraumatisches Nahtmaterial nicht vergessen werden.

Dieser Artikel erschien erstmals in "Wir in der Praxis", Heft 2/2015, S. 24

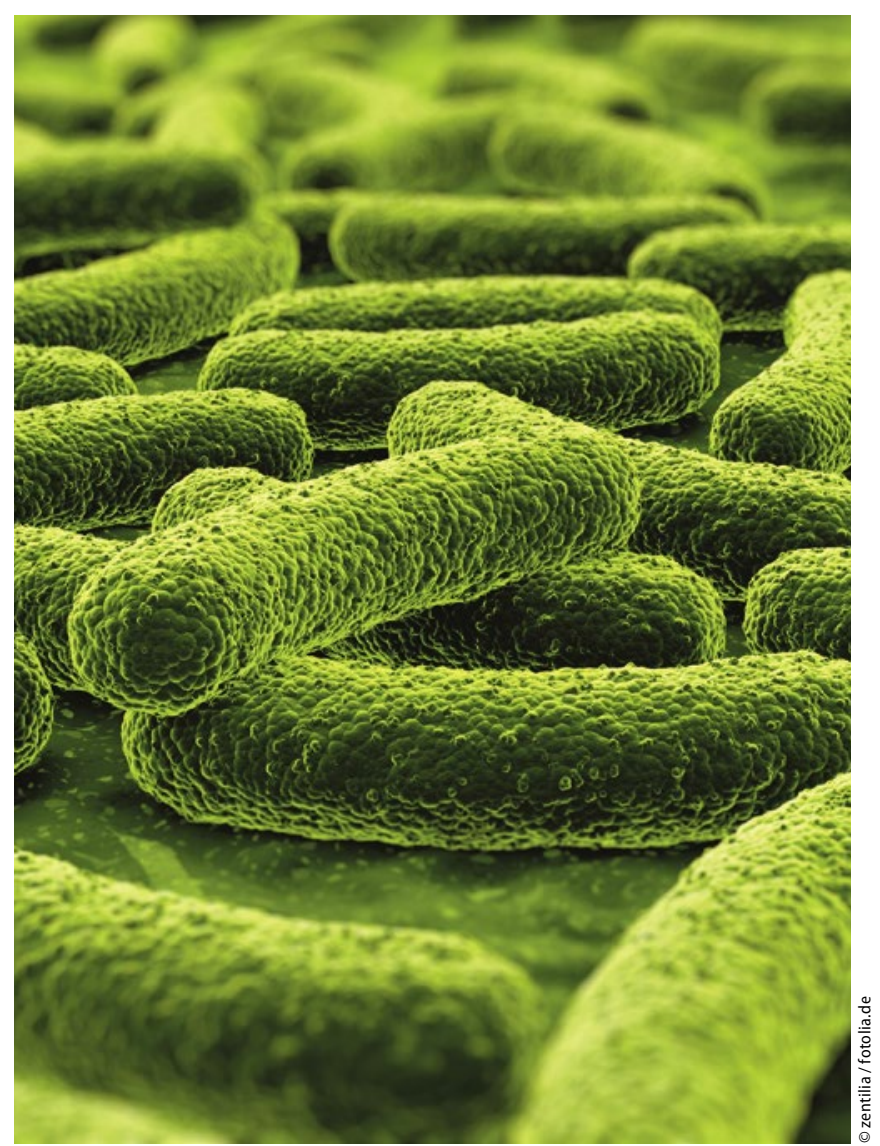

